\title{
A European pilot quality assessment scheme for molecular diagnosis of Huntington's disease
}

\author{
M onique Losekoot ${ }^{1}$, Bert Bakker ${ }^{1}$, Franco L accone ${ }^{2}$, Su Stenhouse ${ }^{3}$ and R ob Elles ${ }^{4}$ \\ ${ }^{1}$ D N A -diagnostic section, M G C -D epartment of H uman G enetics, L eiden University M edical Centre, L eiden, The \\ $\mathrm{N}$ etherlands \\ ${ }^{2}$ Institute of $H$ uman $\mathrm{G}$ enetics, U niversität G öttingen, G ermany \\ ${ }^{3}$ E uropean M olecular G enetics Q uality N etwork, N orthern Regional G enetics Service, N ewcastle upon Tyne \\ ${ }^{4}$ C o-ordinator, E uropean M olecular G enetics Q uality N etwork, U niversity D epartment of M edical G enetics and \\ Regional G enetics Service, St M ary's H ospital, M anchester, U K
}

\begin{abstract}
This paper reports a E uropean pilot External Q uality A ssessment (E Q A) scheme for the molecular diagnosis of $H$ untington's disease (H D). The E uropean M olecular $G$ enetics $Q$ uality Network (E MQN) chose HD as a relatively simple assay that allows a range of difficulty in terms of technical competence and interpretation. Fourteen centres from 12 different countries participated. The scheme organiser provided five cases together with mock clinical information. The participating laboratories were asked to complete the analyses and return the reports in English to their normal laboratory format within a fixed period. The scheme demonstrates a level of potential misdiagnosis in molecular analysis of HD as well as a wide variety in way of reporting laboratory results. O verall $9 / 146(6.2 \%)$ of alleles fell outside the set limits, and the rate of misdiagnosis was $1 / 78(1.3 \%)$. A closer estimate of diagnostic accuracy will require expansion of the scheme.
\end{abstract}

Keywords: E uropean; quality; molecular; diagnosis; H untington's disease

\section{Introduction}

Diagnostic molecular genetics is a relatively new discipline in pathology and must quickly develop systems for maintaining a standard level of quality. ${ }^{1}$ Since genetic testing for inherited disease has a high profile in the news media, there is a risk that misdiagnosis or poor practice could undermine the confidence of the public, clinicians and governments in this developing sector. A first aim in introducing quality

Correspondence: R ob Elles, Co-ordinator, EM QN, c/o U niversity $D$ epartment of Medical $G$ enetics and $R$ egional G enetics Service, St M ary's H ospital, M anchester, M 130] H, UK. Tel: 441612766129; Fax: 441612766606; E mail relles@hgmp.mrc.ac.uk

R eceived 8 A pril 1998; revised 3 July 1998; accepted 15 July 1998 standards must be to measure the current average standard in laboratories, whilst a second aim is to raise this average over time. External Q uality A ssessment (EQA) is one of the mechanisms to measure quality and encourage a raising of standards.

EQA involves the comparison of a laboratory output against a fixed 'standard'. ${ }^{2}$ Testing material is supplied from an external source (the EQA provider), and is followed by the performance of diagnostic tests and the return by a fixed time of a laboratory report by the participants. One expert or more assesses the reports on agreed marking criteria. Individual comments are returned to the participants along with scores on the accuracy of genotyping and interpretation of the results in the light of the clinical data supplied. In addition a general overview of the scheme is provided with trends in performance and interpretation. 
If EQA is to be effective, laboratories must take note of the assessors' comments and introduce a mechanism for making changes in their practice to improve the quality of their output and their EQA scores. In some national EQA schemes persistent poor performance by a centre may result in formal mechanisms being invoked to ensure changes in practice. ${ }^{2}$ In contrast, international schemes can only change laboratory practice by an educational influence. N ational or singledisease EQA schemes have demonstrated both the requirement for standards and the feasibility of $E$ uropean co-operation. ${ }^{3,4}$ This pilot scheme aimed to test the feasibility of a European scheme in a new disease area (HD). It was also an extension from a technical scheme into a scheme that tested the ability of laboratories to interpret data also in the light of clinical information.

\section{Materials and Methods}

$\mathrm{H}$ untington's disease was chosen as being technically relatively straightforward yet allowing a range of mock clinical referrals across a range of difficulty in terms of technical competence and interpretative complexity. The standard assay for the presence of the Huntington's disease mutation consists of a single $P C R$ incorporating the $(C A G)_{n}$ repeat region in the IT 15 (H untington) gene. ${ }^{5,6}$ A lleles differ in size according to the number of triplet units present. Normal individuals have alleles in the range of 9- 35 repeats; affected individuals have over 39 repeats. ${ }^{7}$ Normal individuals with over 39 repeats are not seen, whilst affected individuals with less than 36 repeats are extremely rare. The ambiguous range (reduced penetrance alleles), where caution in reporting is advised, covers 36-39 repeats. 8,9 There is evidence that repeats in the $29-35$ repeat range are prone to expansion during meiosis. ${ }^{10,11}$

The centre which agreed to act as provider (L eiden) had not acted as an EQA provider previously. The scheme, intended for 10-15 participants, was commissioned by E M Q N in January 1997 and the timetable below was drawn up as a guide for the provider and participants:

\begin{tabular}{|c|c|c|c|}
\hline February-A pril & & May & A ugust \\
\hline $\begin{array}{l}\text { Validate cell lir } \\
\text { participants, pr } \\
\text { documentation }\end{array}$ & $\begin{array}{l}\text { e samples, select } \\
\text { pare }\end{array}$ & $\begin{array}{l}\text { Send } \\
\text { out } \\
\text { samples }\end{array}$ & $\begin{array}{l}\text { D eadline for } \\
\text { return of } \\
\text { reports }\end{array}$ \\
\hline eptember & O ctober & & er \\
\hline I ark R eports & $\begin{array}{l}\text { R eturn indivi } \\
\text { comments to }\end{array}$ & & $\begin{array}{l}\text { erview } \\
\text { me }\end{array}$ \\
\hline
\end{tabular}

The availability of the scheme was advertised through E uropean national contacts of the European Molecular Genetics Quality Network (EMQN), and the European Directory of DNA Laboratories (EDDNAL). ${ }^{12}$ They were asked to nominate one laboratory in their country. A total of 14 laboratories from G ermany, I reland, Spain, B elgium, I taly, the UK, France (two centres), Finland, Denmark, Austria,
Sweden, the Czech Republic and the USA (which provides $H D$ testing for E urope) participated in the pilot scheme. Centres were assigned a code number and asked to identify their returns only by this number to maintain anonymity.

Samples were obtained from the European Cell Culture Collection (ECCC), Porton Down, Wiltshire, UK (Case 2), the Cell Bank, Department of M edical Genetics, St M ary's H ospital M anchester, UK (C ase 3), and from the D epartment of $\mathrm{H}$ uman $\mathrm{G}$ enetics, L eiden, The N etherlands (Cases 1, 4, 5a and $5 \mathrm{~b}$ ). A s a 'comparative standard' the averages of the genotype results were taken from the 13 participating laboratories, and the EQA provider was used. This is not an ideal standard and for the next scheme the standard itself will be set by three reference laboratories. DNA solutions in $10 \mathrm{mM}$ Tris, $1 \mathrm{mM}$ EDTA at a concentration of $0.1 \mu \mathrm{g} / \mu \mathrm{l}(2 \mu \mathrm{g}$ total) were aliquoted into $0.5 \mathrm{ml}$ microfuge tubes and labelled appropriately (cases 1-5). Samples were mailed to the participants together with the case documentation. The samples were matched to clinical details to form five mock referrals. Centres were asked to type the samples according to their normal methods and procedures and to return the results in their normal laboratory report format (in English) by a deadline, which was approximately 13 weeks from the mailing.

It was intended that the first four cases (1-4) should be representative of commonly encountered referrals. Cases $5 a$ and $b$ were considered more unusual and difficult. The documentation detailing the cases as sent to the participants is reproduced below.

\section{Case 1}

A 35-year-old female requests predictive testing for $\mathrm{H}$ untington's disease. $\mathrm{H}$ er father was affected with this disease but is not available for testing. She is referred by a clinical geneticist.

\section{Case 2}

This individual has been diagnosed clinically as being affected with $\mathrm{H}$ untington's disease. The neurologist requests confirmation of the diagnosis.

\section{Case 3}

This 64-year-old individual has a five year history of movement disorder. The family history is negative for H untington's disease; the neurologist requests confirmation of the diagnosis.

\section{Case 4}

A 24-year-old female requests predictive testing for $\mathrm{H}$ untington's disease. $\mathrm{H}$ er father was affected with this disease but has never been tested. A $n$ expanded CA G repeat ( 45 repeats) was found in a patient in another part of this family. She is referred by a clinical geneticist.

\section{Case 5}

Two sisters, 35 and 32 years of age respectively, request predictive testing for $\mathrm{H}$ untington's disease. Their father is affected with the disease and has a 46 and 18 CA G -allele, they don't want to involve the mother who was recently hospitalized in a psychiatric institution. The elder sister has two small children; the younger sister wants to start a family. They are referred by a clinical geneticist. 


\section{Results}

Of the 14 laboratories which participated in the scheme, 13 sent returns by the deadline. In this small scheme no administrative problems were reported to have been significant. However, identifying the logos were not always completely removed to preserve anonymity and not all reports included the laboratory identifying code.

In general, no details were asked or given about assay methods or primer sequences, although this could be a subject of the next scheme or a best-practice meeting. However, as far as the assessors could gather, all samples were assayed primarily by PCR and a subsequent run on a polyacrylamide gel. The products were imagined either by autoradiography or by fluorescent fragment analysis. Two laboratories returned X -ray film with the results. One centre used Southern blot analysis as an additional technique in case 1 , although the quantities of material provided were not designed with this method in mind. A nother centre sequenced the CA G -repeats in Cases $5 a$ and $b$.

\section{Marking}

The returns were assessed by a panel of four ( $M L, B B$, $S S$, and $F L)$ from the Netherlands, the $U K$ and
Germany. A ssessors were chosen as experts in their field and for having experience of E QA. They met once to consider the returns. The assessors decided that for CA G -repeats up to 40 an error of \pm 1 CAG and in the range over 40 CAG's an error of \pm 3 repeats was acceptable. Genotypes were scored numerically: each case could produce a maximum score of 2.00 points. For an allele recorded outside the set error limits 0.5 points were deduced, whereas an allele assigned outside the accepted range (normal or expanded) produced a score of zero for that case. The reported allele sizes are given in Table 1 and the genotyping scores are shown in Table 2.

Thirteen laboratories each sent returns on six cases making a total of 156 alleles to be assessed. Ten alleles were not sized, leaving 146 alleles that could be compared against the standard (Table 1). O ne centre consistently sized alleles in the normal (unaffected) range outside the limits set, although in none of the cases would the genotyping error have resulted in a misdiagnosis. O verall 9/146 (6.2\%) of alleles fell outside the set limits for the assay in this exercise. O ne centre made an allele size assignment outside the accepted normal and pathological ranges which would have resulted in a diagnostic error (in Case 4). The rate of misdiagnosis in this series was $1 / 78(1.3 \%)$.

Table 1 Reported allele sizes

\begin{tabular}{|c|c|c|c|c|c|c|c|c|c|c|c|c|}
\hline \multirow{2}{*}{ L ab code } & \multicolumn{2}{|c|}{ case 1} & \multicolumn{2}{|c|}{ case 2} & \multicolumn{2}{|c|}{ case 3} & \multicolumn{2}{|c|}{ case 4} & \multicolumn{2}{|c|}{ case $5 a$} & \multicolumn{2}{|c|}{ case $5 b$} \\
\hline & 1 & 2 & 1 & 2 & 1 & 2 & 1 & 2 & 1 & 2 & 1 & 2 \\
\hline $\begin{array}{l}\text { provider } \\
1^{\mathrm{a}}\end{array}$ & 17 & 17 & 19 & 45 & 17 & 18 & 17 & 65 & 37 & 46 & 36 & 46 \\
\hline 2 & 17 & 17 & 19 & 44 & 17 & 18 & 17 & 63 & 36 & 44 & 35 & 44 \\
\hline 3 & 16 & 16 & 18 & 42 & 16 & 17 & 16 & 61 & 35 & 42 & 34 & 42 \\
\hline 4 & 17 & 17 & 19 & 43 & 17 & 18 & 17 & 62 & 36 & 43 & 35 & 43 \\
\hline 5 & 16 & 16 & 19 & 44 & 17 & 18 & 17 & 63 & 35 & 44 & 36 & 44 \\
\hline $6^{b}$ & $\begin{array}{l}\text { expar } \\
\text { absen }\end{array}$ & sion & $\begin{array}{l}\text { expan } \\
\text { prese }\end{array}$ & on & $\begin{array}{l}\text { expan } \\
\text { absen }\end{array}$ & & $\begin{array}{l}\text { expar } \\
\text { prese }\end{array}$ & & 37 & 45 & 35 & 44 \\
\hline 7 & 17 & 17 & 19 & 43 & 17 & 18 & 17 & 68 & 36 & 44 & 35 & 44 \\
\hline 8 & 17 & 17 & 19 & 44 & 17 & 18 & 17 & 62 & 36 & 44 & 35 & 44 \\
\hline 9 & 17 & 17 & 19 & 44 & 17 & 18 & 17 & 62 & 36 & 44 & 35 & 44 \\
\hline & \pm 1 & \pm 1 & \pm 1 & \pm 1 & \pm 1 & \pm 1 & \pm 1 & \pm 1 & \pm 1 & \pm 1 & \pm 1 & \pm 1 \\
\hline 10 & 22 & 22 & 24 & 45 & 19 & 23 & 22 & 64 & 37 & 46 & 38 & 46 \\
\hline $11^{\mathrm{c}}$ & \pm 18 & \pm 18 & \pm 20 & \pm 45 & \pm 18 & \pm 19 & \pm 18 & \pm 28 & \pm 38 & \pm 47 & \pm 37 & \pm 46 \\
\hline 12 & 17 & 17 & 19 & 43 & 17 & 18 & 17 & 61 & 36 & 43 & 35 & 43 \\
\hline 13 & 16 & 16 & 18 & 42 & 16 & 17 & 16 & 60 & 35 & 43 & 34 & 43 \\
\hline 14 & 18 & 18 & n.r. & 46 & 16 & 19 & n.r. & 62 & 36 & 45 & 36 & 46 \\
\hline average & 17.4 & 17.4 & 19.45 & 44 & 17.08 & 18.5 & 17.45 & 63 & 36.2 & 44.4 & 35.5 & 44.3 \\
\hline max. deviation & 4.58 & 4.58 & 4.55 & 2 & 1.92 & 4.5 & 4.55 & 5 & 1.8 & 2.6 & 2.5 & 2.3 \\
\hline
\end{tabular}

' $\mathrm{L}$ ab 01 did not return results;

${ }^{b} L$ ab 06 stated whether the expansion was present (positive) or absent (negative);

' $L$ ab 11 stated that all allele sizes were approximate without quoting error limits;

n.r.: not reported 
Table 2 Genotyping scores

\begin{tabular}{llllllll}
\hline $\mathrm{L}$ ab & case & case & case & case & case & case & \\
code & 1 & 2 & 3 & 4 & $5 \mathrm{a}$ & $5 \mathrm{~b}$ & average \\
\hline 2 & 2.00 & 2.00 & 2.00 & 2.00 & 2.00 & 2.00 & 2.00 \\
3 & 2.00 & 2.00 & 2.00 & 2.00 & 2.00 & 2.00 & 2.00 \\
4 & 2.00 & 2.00 & 2.00 & 2.00 & 2.00 & 2.00 & 2.00 \\
5 & 2.00 & 2.00 & 2.00 & 2.00 & 2.00 & 2.00 & $2.00^{\mathrm{a}}$ \\
6 & 2.00 & 2.00 & 2.00 & 2.00 & 2.00 & 2.00 & $2.00^{\mathrm{a}}$ \\
7 & 2.00 & 2.00 & 2.00 & 2.00 & 2.00 & 2.00 & $2.00^{\mathrm{b}}$ \\
8 & 2.00 & 2.00 & 2.00 & 2.00 & 2.00 & 2.00 & 2.00 \\
9 & 2.00 & 2.00 & 2.00 & 2.00 & 2.00 & 2.00 & 2.00 \\
10 & 1.50 & 2.00 & 1.50 & 2.00 & 2.00 & 1.50 & $1.75^{\mathrm{a}}$ \\
11 & 2.00 & 2.00 & 2.00 & 0 & 2.00 & 2.00 & 1.66 \\
12 & 2.00 & 2.00 & 2.00 & 2.00 & 2.00 & 2.00 & 2.00 \\
13 & 2.00 & 2.00 & 2.00 & 2.00 & 2.00 & 2.00 & 2.00 \\
14 & 2.00 & 2.00 & 2.00 & 2.00 & 2.00 & 2.00 & $2.00^{\mathrm{ac}}$ \\
average & 1.96 & 2.00 & 1.96 & 1.85 & 2.00 & 1.96 & 1.95 \\
\hline
\end{tabular}

${ }^{2}$ The intermediate allele in individual 5a was 1 CA G-repeat longer than in individual $5 \mathrm{~b}$. No points were subtracted;

${ }^{b}$ In case 4 the expanded allele was 4 CA G -repeats longer than average. No points were subtracted;

${ }^{c} \mathrm{~N}$ ot all repeat lengths were reported.

Interpretation was considered to be of secondary importance in this pilot exercise due to the problems of marking reports in English - not the first language of most participants, and because no E uropean guidelines for reporting are currently available. Nonetheless, interpretation was included to evaluate to what extent this could form part of European EQA schemes as an educational exercise, but it was not scored numerically. Laboratories were assessed and individual comments formulated according to the general criteria set out below. Some of the points apply to HD in particular but many of them are applicable to all types of reporting.

In an ideal report the assessors were looking for the following points:

- The layout of a report should give priority to patient information, results and conclusion. A ny additional information such as laboratory protocols and explanatory notes should be considered supplementary and should come at the end of the report or be separated from the main text.

- The reason for referral should be restated in a clear and concise way.

- No errors in transcription of patient information or typographical errors in the results and conclusion should be evident.

- A report should explain the results in a clear and concise manner that can be understood by a nonspecialist. The possibility that the report may be read by people other than the original referring clinician, such as a general practitioner or patients themselves, should be considered.

- All reports should be checked and signed by two competent molecular geneticists or equivalent.

- A standard wording for reports should be avoided.

In addition the assessors identified the following points relevant to $H D$ :

- The testing methods should be stated and any limitations of the test clarified. All allele sizes should be given as 'approximate'.

- Care should be taken not to assign undue significance to allele sizes in the affected range. However, the significance of 'intermediate' and 'low penetrance' alleles needs to be explained.

- It is also important to state the conclusion unambiguously, for example:

'This result excludes (or confirms) a diagnosis of HD.'

'This result excludes (or confirms) a diagnosis of HD.'

'This result predicts the patient will (or will not) develop HD.'

In the context of HD the use of the term 'abnormal' or 'normal' applied to alleles is considered to be inappropriate.

- A distinction should be clear between predictive reports and reports diagnostic of HD.

- If a diagnosis of HD is confirmed some indication of the implications for other family members should be given.

In addition the assessors formulated 13 specific key interpretative points relevant to the cases offered in the scheme and recorded whether in their opinion a laboratory had adequately covered that point in the text of the report. These points are detailed in Table 3. $E$ ach laboratory received an individual report from the assessors commenting on its interpretative performance.

Most of the 13 key interpretative points were mentioned by a majority of the reports, demonstrating some consensus even in the absence of agreed reporting guidelines. M ost laboratories matched a majority of these criteria in their reports. Four centres produced 
reports in which a majority of the interpretative points were not mentioned (Table 3).

\section{Conclusions}

In this pilot scheme the procurement and validation of samples, assembling of cases, quantity of samples, meeting the timetable and responding to the questions of participants did not present great problems. The assembly of an expert panel and marking returns was similarly relatively straightforward. However, for schemes involving a large number of participants, or a test which requires larger amounts of DNA and includes a wider range of methods and/or possible outcomes, might be more difficult. Certainly the administrative, technical and scientific resources required to provide an External Q uality A ssessment scheme to a high standard should not be underestimated. The costs of this pilot exercise are estimated at about $8000 \mathrm{ecu}$, including personnel.

Since the inclusion of allele size data in clinical reports is still under discussion, it was not normal reporting policy at all centres. Failure to make clear to the laboratories that allele sizes were to be compared was a weakness of the pilot scheme and will be corrected next time. Fortunately most laboratories returned this data enabling a technical comparison.

A Ithough no guidelines were available, the assessors assumed that participating centres were aware of the 'Guidelines for the molecular genetics predictive test in $\mathrm{H}$ untington's disease' ${ }^{4}$ as well as recently published international literature, and that they incorporated this knowledge into their reports. The exercise demonstrated that interpretation could form part of a crosslanguage EQA scheme.

The scheme revealed a level of potential misdiagnosis among laboratories offering molecular diagnosis for Huntington's disease. A closer estimate of

Table 3 Interpretative points relevant to each case

\begin{tabular}{|c|c|c|c|c|c|c|c|c|c|c|c|c|c|c|}
\hline \multirow{2}{*}{ Interpretative criteria } & \multicolumn{13}{|c|}{ L ab code } & \multirow{2}{*}{$\begin{array}{l}\text { total } \\
\mathrm{Y} / \mathrm{N}\end{array}$} \\
\hline & 2 & 3 & 4 & 5 & 6 & 7 & 8 & 9 & 10 & 11 & 12 & 13 & 14 & \\
\hline $\begin{array}{l}\text { Case } 1 \\
\text { Subject homozygous for } \\
\text { normal allele }\end{array}$ & $\mathrm{N}$ & Y & Y & Y & $\mathrm{N}$ & Y & Y & Y & $\mathrm{N}$ & $\mathrm{Y}$ & Y & $\mathrm{Y}$ & $Y$ & $10 / 3$ \\
\hline $\begin{array}{l}\text { indication that the other } \\
\text { allele might be missed on PCR }\end{array}$ & $\mathrm{N}$ & Y & Y & Y & $\mathrm{N}$ & $\mathrm{N}$ & $\mathrm{N}$ & Y & $\mathrm{N}$ & Y & Y & Y & Y & $8 / 5$ \\
\hline clear phrasing of the risk & Y & Y & $\mathrm{N}$ & Y & $\mathrm{N}$ & $\mathrm{N}$ & $\mathrm{N}$ & Y & Y & Y & Y & Y & Y & $9 / 4$ \\
\hline confirm diagnosis in father & $\mathrm{N}$ & $\mathrm{N}$ & $\mathrm{N}$ & $Y$ & $Y$ & $\mathrm{~N}$ & $\mathrm{~N}$ & $Y$ & $\mathrm{~N}$ & $Y$ & $Y$ & $Y$ & $Y$ & $7 / 6$ \\
\hline $\begin{array}{l}\text { Case } 2 \\
\text { diagnosis HD was } \\
\text { confirmed }\end{array}$ & Y & Y & $\mathrm{N}$ & $Y$ & $Y$ & $\mathrm{~N}$ & Y & $\dot{Y}$ & Y & $Y$ & $Y$ & $Y$ & $Y$ & $11 / 2$ \\
\hline $\begin{array}{l}\text { mention implications for } \\
\text { other family members }\end{array}$ & $\mathrm{N}$ & $\mathrm{N}$ & $\mathrm{N}$ & Y & $\mathrm{N}$ & $Y$ & $\mathrm{~N}$ & $Y$ & $\mathrm{~N}$ & $\mathrm{~N}$ & $\mathrm{~N}$ & $Y$ & $Y$ & $5 / 8$ \\
\hline $\begin{array}{l}\text { Case } 3 \\
\text { HD excluded as cause of } \\
\text { movement disorder }\end{array}$ & $Y$ & Y & Y & Y & $Y$ & $\mathrm{~N}$ & $Y$ & $Y$ & $\mathrm{~N}$ & Y & $\mathrm{N}$ & $Y$ & $Y$ & $10 / 3$ \\
\hline $\begin{array}{l}\text { Case } 4 \\
\text { phasing the risk in a } \\
\text { predictive manner }\end{array}$ & Y & $Y$ & $\mathrm{~N}$ & Y & $\mathrm{N}$ & $\mathrm{N}$ & Y & $Y$ & $\mathrm{~N}$ & MD & $\mathrm{N}$ & $Y$ & $Y$ & $7 / 5$ \\
\hline $\begin{array}{l}\text { Case } 5 \\
\text { Separate reports for the two } \\
\text { subjects }\end{array}$ & $Y$ & $\mathrm{~N}$ & $\mathrm{~N}$ & $\mathrm{~N}$ & $Y$ & $Y$ & $\mathrm{~N}$ & $\mathrm{~N}$ & Y & $\mathrm{N}$ & $Y$ & $Y$ & $Y$ & $7 / 6$ \\
\hline clear phrasing of the risk & Y & Y & $\mathrm{N}$ & $\mathrm{N}$ & $\mathrm{N}$ & $\mathrm{N}$ & $\mathrm{N}$ & Y & $\mathrm{N}$ & Y & $\mathrm{N}$ & Y & Y & $6 / 7$ \\
\hline $\begin{array}{l}\text { discuss intermediate/borderline/ } \\
\text { reduced penetrance allele }\end{array}$ & Y & $\mathrm{N}$ & Y & Y & Y & Y & N & Y & $\mathrm{N}$ & Y & $\mathrm{N}$ & Y & Y & $9 / 4$ \\
\hline $\begin{array}{l}\text { mention possibility of expansion/ } \\
\text { contraction of alleles during meiosis }\end{array}$ & Y & $\mathrm{N}$ & Y & Y & Y & Y & $\mathrm{N}$ & Y & $\mathrm{N}$ & Y & $\mathrm{N}$ & Y & Y & $9 / 4$ \\
\hline $\begin{array}{l}\text { discuss relevance of testing } \\
\text { mother }\end{array}$ & Y & $\mathrm{N}$ & $\mathrm{N}$ & Y & Y & $\mathrm{N}$ & $\mathrm{N}$ & Y & $\mathrm{N}$ & Y & $\mathrm{N}$ & $\mathrm{N}$ & $Y$ & $6 / 7$ \\
\hline
\end{tabular}

$\mathrm{Y}=$ interpretative point mentioned in text; $\mathrm{N}=$ not mentioned or inadequately dealt with; $\mathrm{MD}=$ genotype error resulting in misdiagnosis. 
diagnostic accuracy may be available if the scheme is expanded. O ne aim of the scheme is to raise standards of diagnostic testing. Individual comments to laboratories, feedback and the interpretative element of the scheme forms part of this effort.

\section{Acknowledgements}

This work was supported by the European Molecular G enetics Q uality N etwork.

\section{References}

1 Cuppens $\mathrm{H}$, Cassiman J: Q uality control study of CFTR mutation screening in 40 different European laboratories - the E uropean concerted action on cystic fibrosis. E ur J H um G enet 1995; 3: 235-245.

2 Stenhouse S, Middleton-Price $\mathrm{H}$ : Q uality assurance in molecular diagnosis: the UK experience. In Elles R (ed). Molecular Diagnosis of $G$ enetic $D$ iseases H umana Press: Totowa, NJ, 1996; pp 341-352.

3 Huntington's Disease Collaborative R esearch Group: A novel gene containing a trinucleotide repeat that is expanded and unstable on H untington's disease chromosomes. Cell 1993; 72: 971-983.
4 International Huntington's A ssociation and the World Federation of Neurology Research Group on Huntington's Chorea: Guidelines for the molecular genetics predictive test in Huntington's disease. J M ed G enet 1994; 31: 555-559.

5 Goldberg Y P, A ndrew SE, Clarke LA, Hayden M R : A PCR method for accurate assessment of trinucleotide repeat expansion in $\mathrm{H}$ untington disease. $\mathrm{H}$ um $\mathrm{M}$ ol $\mathrm{G}$ enet 1993; 2: 635-636.

6 Warner JP, Barron LH, Brock DJ: A new polymerase chain reaction ( $P C R$ ) assay for the trinucleotide repeat that is unstable and expanded on Huntington's disease chromosomes. M ol Cell Probes 1993; 7: 235-239.

7 K remer B, Goldberg P, A ndrew SE et al: A worldwide study of the $\mathrm{H}$ untington's disease mutation. The sensitivity and specificity of measuring CA G repeats. N Engl J Med 1994; 330: 1401-1406.

8 Rubinsztein DC, Leggo J, Coles R et al: Phenotypic characterisation of individuals with 30-40 CA G repeats in the Huntington's disease gene reveals HD cases with 36 repeats and apparently normal elderly individuals with 36-39 repeats. A m J H um G enet 1996; 59: 16-22.

9 McNeil SM, Novelletto A, Srinidhi J et al: Reduced penetrance of $\mathrm{H}$ untington's disease mutation. $\mathrm{H}$ um $\mathrm{M}$ ol G enet 1997; 6: 775-779.

$10 \mathrm{M}$ yers $\mathrm{RH}, \mathrm{M}$ acD onald $\mathrm{ME}$, Koroshetz WJ et al: D e novo expansion of a (CAG)n repeat in sporadic Huntington's disease. $N$ at $G$ enet 1993; 5: 168-173.

11 Goldberg Y P, K remer B, A ndrew SE et al: Molecular analysis of new mutations for Huntington's disease: intermediate alleles and sex of origin effects. $\mathrm{N}$ at $\mathrm{G}$ enet 1993; 5: 174-179.

12 European Directory of DNA Laboratories: http/ /www.eddnal.com 